\title{
A HISTORICIDADE DOS DIREITOS HUMANOS E OS PENSAMENTOS DE BOBBIO E ARENDT NA CONSTRUÇÃO DO DIREITO AO TRABALHO E AO LAZER
}

\author{
THE HISTORICITY OF HUMAN RIGHTS AND BOBBIO'S AND ARENDT'S THOUGHTS ON THE \\ CONSTRUCTION OF THE RIGHT TO WORK AND LEISURE
}

Daniela Menin ${ }^{1}$

${ }^{1}$ Bacharel em Direito pelo Centro Universitário da Grande Dourados (1998), Bacharel em Teologia pelo Seminário Presbiteriano Renovado Brasil Central (2009) de Anápolis/ GO, pós-graduação em Direito Público pela Universidade Anhanguera-Uniderp (2012), Advogada, Mestranda em Fronteiras e Direitos Humanos pela Universidade Federal da Grande Dourados. Pesquisa Direito ao Lazer do Trabalhador e outros aspectos do Direito do Trabalho.

E-mail: danameninadv@gmail.com
MENIN, D. A historicidade dos direitos humanos e os pensamentos de Bobbio e Arendt na construção do direito ao trabalho e ao lazer. Akrópolis Umuarama, v. 26, n. 1, p. 23-37, jan./jun. 2018.

DOI: 10.25110/akropolis.v26i1.6254

Resumo: A partir das premissas apontadas por Norberto Bobbio em sua obra "A Era dos Direitos" e por Hannah Arendt, em sua obra "A condição Humana", verifica-se a historicidade dos Direitos Humanos e sua influência no ordenamento jurídico brasileiro, particularmente na Constituição Federal de 1988 e na construção teórica, positivação e efetividade do direito do trabalho e do direito ao lazer do trabalhador. Neste sentido, o enfoque principal está na historicidade dos Direitos Humanos defendida por Bobbio e na importância do direito ao trabalho e ao lazer destacado por Hannah Arendt.". Também recebe destaque neste trabalho as Cartas Encíclicas Pacem in Terris e Rerum Novarum, que figuram como elemento importante na historicidade dos Direitos Humanos, inclusive na construção do Direito do trabalho.

Palavras-chave: direitos humanos; direitos fundamentais; direito do trabalho; direito ao lazer.

Abstract: Based on Norberto Bobbio' assumptions in "The Age of Rights" and Hannah Arendt's assumptions in "The Human Condition", the historicity of Human Rights and its influence in the Brazilian legal system can be observed, particularly in the 1988 Federal Constitution and in the theoretical construction, positive results and effectiveness of labor law and the worker's right to leisure. In this sense, it focuses on the historicity of Human Rights as advocated by Bobbio and on the importance of the right to work and leisure emphasized by Hannah Arendt. This paper also emphasizes the Encyclical Letters Pacem in Terris and Rerum Novarum, which are considered important elements in the historicity of Human Rights, including in the construction of Labor Law.

Keywords: human rights; fundamental rights; Labor law; Right to leisure. 


\section{INTRODUÇÃO}

Compreender a construção conceitual dos Direitos Humanos e sua positivação sob a perspectiva histórica é de fundamental importância para poder enfrentar a discussão sobre o alcance universal dos direitos humanos. Ainda que, segundo a Declaração Universal dos Direitos Humanos da Organização das Nações unidas de 1948, todos nasçam iguais e portadores de direitos, a história da humanidade tem demonstrado que cada direito e cada garantia assegurados ao indivíduo são frutos de lutas históricas. Ou foram respostas às barbáries ocorridas mundialmente, ou resultado de acontecimentos históricos e lutas sociais, todos com o objetivo comum de emancipar o indivíduo, desenvolvê-lo, promover a sua dignidade como pessoa humana e consequentemente, criar uma sociedade mais justa e pacífica. A compreensão dessa trajetória histórica é fundamental para analisar a efetividade desses direitos, uma vez que, embora positivados, muitos padecem de evolução e efetivação.

Também é possível observar o caráter de universalidade dos direitos humanos, na medida em que a Declaração de 1948 influenciou não somente a elaboração de outras declarações protetivas, mas também várias Constituições.

O estudo tem caráter analítico e busca extrair dos autores citados o fundamento para a análise dos reflexos da Teoria Geral dos Direitos Humanos na construção do ordenamento jurídico brasileiro, mais especificamente no que se refere ao direito ao trabalho e ao lazer. Aborda os aspectos gerais dos direitos humanos, com ênfase em sua historicidade, explanando de que forma a Declaração Universal dos Direitos Humanos de 1948 refletiu no mundo e na criação de dispositivos que promovessem e preservassem tais direitos. $O$ artigo também explana a respeito de outros aspectos importantes dos Direitos do Homem, como indivisibilidade e heterogenia, abordando também a necessidade que ainda há de efetivação de alguns direitos.

Os reflexos da Declaração Universal dos Direitos Humanos também na construção da Constituição Federal de 1988, que por sua vez, positivou vários direitos sociais fundamentais, inclusive o direito ao trabalho e ao lazer.

\section{ELEMENTOS HISTÓRICOS DOS DIREITOS HUMANOS}

Para falar de Direitos Humanos é preciso entendê-los como fruto de construções jurídicas ao longo da história, voltados para o aprimoramento da sociedade e para uma convivência pacífica entre os indivíduos e também entre os povos, visando à promoção da dignidade humana para todos os indivíduos. A este respeito, Piovesan (2015, p.188) acrescenta que "enquanto reinvindicações morais, os direitos humanos são fruto de um espaço simbólico de luta e ação social, na busca por dignidade humana, o que compõe um construído axiológico emancipatório".

É a partir dessa premissa que Norberto Bobbio (2004) entende ser possível verificar que os mais diversos contextos históricos, associados às ideologias diferentes e a clamores e necessidades específicas de vários grupos de indivíduos, compuseram o cenário para o surgimento de um dos mais importantes marcos internacionais de positivação dos Direitos Humanos: A Declaração dos Direitos Humanos da Organização das Nações Unidas, em 1948. ${ }^{2}$

Neste sentido, Bobbio (2004) ressalta em sua obra, "A era dos Direitos", que não existe um único fundamento que justifica a construção da Declaração de 1948, até mesmo pelo fato de que houve todo um processo dinâmico e dialéti$\mathrm{co}$, de forma que a elaboração formal do documento, ponto de partida de para a proteção desse direitos, foi uma resposta, uma reação global às atrocidades e barbáreis praticadas principalmente no segundo pós-guerra.

Ou seja, a Declaração dos Direitos Humanos foi construída como resposta aos anseios da humanidade para uma convivência coletiva harmônica e livre, por meio de conquistas que se solidificaram ao longo dos anos.

Do ponto de vista teórico, sempre defendi e continuo a defender, forta-

\footnotetext{
${ }^{2} \mathrm{~A}$ Europa foi cenário para que no século XIX, surgissem as primeiras constituições, com destaque para a siciliana de 1812, a espanhola de Cádiz, de 1812, a francesa de 1814 e posteriormente de 1848, a portuguesa de 1822 e a belga de 7 de fevereiro de 1831 . Tais documentos foram também motivadores para a positivação e consagração normativa dos direitos humanos. E ainda neste mesmo aspecto de importância, é possível citar a Convenção de Genebra que versava sobre a Escravatura, datada de 1926 e também a Relativa ao Tratamento de Prisioneiros de Guerra, de 1929. COMPARATO, Fábio Konder. A afirmação histórica dos direitos humanos. 4. ed. São Paulo: Saraiva, 2005, p. 196-221.
} 
lecido por novos argumentos que os direitos do homem, por mais fundamentais que sejam, são direitos históricos, ou seja, nascidos em certas circunstâncias, caracterizadas por lutas em defesa de novas liberdade contra velhos poderes, e nascidos de modo gradual, não todos de uma vez e nem de uma vez por todas. (2004,p.25)

Tal ensinamento de Bobbio é confirmado pela própria história. Observa-se que a Declaração de 1948 também antecedeu outros importantes documentos que contribuíram para consagrar direitos e garantias fundamentais, servindo de inspiração para Constituições de várias nações e também para que, no âmbito internacional, houvesse a expansão da positivação de vários direitos. Neste sentido, destaca-se a Convenção para a Prevenção e a Repressão do Crime de Genocídio, também de 1948, as Convenções de Genebra sobre a Proteção das Vítimas de Conflitos Bélicos, firmada em 1949, a Convenção Europeia dos Direitos Humanos, data de 1950, os Pactos Internacionais de Direitos Humanos, de 1966, a Convenção Americana de Direitos Humanos, de 1969, e o Estatuto do Tribunal Penal Internacional, de 1998.

Assim, Bobbio ensina que a partir de movimentos e acontecimentos históricos, passou-se à reflexão e posterior conclusão da necessidade de firmar pactos e tratados que pudessem garantir o mínimo de dignidade a qualquer indivíduo. $E$, de fato, muitos outros documentos surgiram no sentido de confirmar o que já havia sido declarado e também para ampliar as conquistas que, embora indispensáveis a qualquer indivíduo, ainda eram bastante recentes e precárias, no que diz respeito a sua efetividade.

É importante ressaltar que vários acontecimentos históricos contribuíram para a construção da positivação dos Direitos Humanos, entre eles, a Revolução Francesa. Os idealistas franceses tinham na frase "liberdade, igualdade e fraternidade" o lema do movimento. Norberto Bobbio (2004) teve a perspicácia de destacar as gerações dos direitos humanos baseados no lema da Revolução Francesa, afirmando que o "desenvolvimento dos direitos do homem passou por três fases" que são as três primeiras gerações/dimensões clássicas.

A primeira geração são direitos de natureza política e civil e foram reconhecidos para a tutela das liberdades públicas. Refletem a liberdade do indivíduo com relação ao Estado, em que este deve abster-se de executar determinados atos para que os direitos do indivíduo sejam gerados, preservados, exercidos, etc. Refletem a passagem do absolutismo para o Estado de Direito, com ênfase na busca da valorização do indivíduo e no estabelecimento de barreiras do poder do Estado. (LAFER,1988). São os direitos individuais e indispensáveis à pessoa humana, entre eles, o direito à locomoção, inviolabilidade de domicílio, correspondência, etc.

Os direitos de segunda geração fazem parte do grupo mais significativo para este estudo, pois nele reside a raiz do direito trabalhista e, consequentemente, do direito ao lazer. Este grupo reflete uma importante conquista para a classe trabalhadora, um segundo momento do capitalismo, com o aprofundamento das relações entre o capital e o trabalho. Este relacionamento fomentou o aparecimento dos direitos chamados sociais, incluindo o seguro social, subsistência, amparo à doença e velhice, etc. $\mathrm{O}$ foco era promover a melhoria da qualidade de vida do cidadão (BOBBIO, 2004). São exemplos desse grupo de direitos as férias remuneradas, o décimo terceiro salário, o salário mínimo, aposentadoria, previdência, etc.

Por fim, destaca-se o grupo de terceira geração, que corresponde aos direitos de fraternidade. O Estado já não protege apenas os interesse individuais e sociais, mas também outro tipo de direitos, decorrentes de sociedades de massa, dos processos de urbanização e industrialização produzidos pelos homens. É como se o Estado estivesse protegendo o homem do próprio homem, por isso também pode ser elencado neste grupo, a proteção às relações de consumo.

Assim, Bobbio ressalta que a Declaração dos Direitos Humanos representa que os valores humanos podem ser positivados e fundamentados, refletindo o consenso de que são válidos para toda a humanidade, contribuindo para formar uma comunidade internacional de pessoas livres e iguais.

\section{OUTROS ASPECTOS DOS DIREITOS HU- MANOS, SEGUNDO NORBERTO BOBBIO}

Norberto Bobbio (2004) entende ser possível verificar que os mais diversos contextos históricos, associados às ideologias diferentes e 
a clamores e necessidades específicas de vários grupos de indivíduos, compuseram o cenário para o surgimento documentos importantes para a compreensão e desenvolvimento dos Direitos Humanos.

Mas para Norberto Bobbio, conceituar o que são os direitos humanos não se resume a dizer que são direitos naturais, pertencentes a todo indivíduo. É preciso também esclarecer que é necessário lutar por eles, para que seu reconhecimento e exercício assegurem o aperfeiçoamento da pessoa humana, e dessa forma, o desenvolvimento da civilização. Importante ressaltar que para Bobbio, os direitos humanos são históricos, que se desenvolveram ao longo dos anos mas que ainda precisam e tem potencial para que seu alcance e desenvolvimento seja ainda maior. É este também o entendimento de importantes estudiosos (ARENDT,2000; LAFER,1988;PIOVESAN, 2015) que além de defenderem a historicidade dos direitos humanos, também ensinam que serão construídos e reconstruídos ao longo do tempo, ainda que, como ensina especificamente Bobbio (2004,p.30), nasçam como direitos naturais universais, desenvolvendo-se como direitos positivos particulares e alcancem a plena realização como direitos positivos universais.

Assim, Bobbio assegura que o valor da pessoa humana é um direito positivo, reconhecido e democratizado, em um primeiro momento, na esfera do ordenamento jurídico interno. Mas que de fato existe a universalização dos direitos humanos e atribui tal fator à Declaração Universal dos Direitos Humanos de 1948, sendo ela um dos principais documentos que promoveram a interdependência de ordenamentos e a positivação internacional de direitos. Essas características, positivação e universalidade, serão marcantes para Bobbio defender a desnecessidade de fundamentação dos direitos humanos, que também rejeita de plano a existência de apenas um único e absoluto fundamento que justifique a existência de todos os Direitos Humanos. Caso existisse este único elemento justificador, haveria óbice para que demais direitos pudessem ser reconhecidos e positivados.

Pois bem: dois direitos fundamentais, mas antinômicos, não podem ter, um e outro, um fundamento absoluto, ou seja, um fundamento que torne um direito e o seu oposto, ambos, inquestionáveis e irresistíveis. Aliás, vale a pena recordar que, historicamente, a ilusão do fundamento absoluto de alguns direitos estabelecidos foi um obstáculo à introdução de novos direitos, total ou parcialmente incompatíveis com aqueles. Basta pensar nos empecilhos colocados ao progresso da legislação social pela teoria jusnaturalista do fundamento absoluto da propriedade: a oposição quase secular contra a introdução dos direitos sociais foi feita em nome do fundamento absoluto dos direitos de liberdade. O fundamento absoluto não é apenas uma ilusão; em alguns casos, é também um pretexto para de fender posições conservadoras. (2004;p. 15).

Mas, também é preciso observar que os direitos humanos são heterogêneos e ainda assim se completam. Um exemplo é de que há os direitos de liberdades, que são aqueles garantidos quando o Estado não intervém, mas também há os direitos que são garantidos apenas com a sua intervenção.

Além disso, os direitos humanos também não são herméticos, uma vez que podem ser ampliados, justamente por serem variáveis. Para Bobbio, é possível afirmar que, apesar de muitos direitos já estarem positivados, outros tantos virão, e isso significa que não existe algum direito que seja inato, mas todos devem ser construídos.

O elenco dos direitos do homem se modificou, e continua a se modificar, com a mudança das condições históricas, ou seja, dos carecimentos e dos interesses, das classes no poder, dos meios disponíveis para a realização dos mesmos, das transformações técnicas, etc. Direitos que foram declarados absolutos no final do século XVIII, como a propriedade sacre et inviolable, foram submetidos a radicais limitações nas declarações contemporâneas; direitos que as declarações do século XVIII nem sequer mencionavam, como os direitos sociais, são agora proclamados com grande ostentação nas recentes declarações. Não é difícil prever que, no futuro, poderão emergir novas pretensões que no momento nem sequer podemos imaginar, como o 
direito a não portar armas contra a própria vontade, ou o direito de respeitar a vida também dos animais e não só dos homens (BOBBIO, 2004).

Assim, os direitos humanos são absolutamente indispensáveis para assegurar a todos uma existência digna, livre e igual. O fato é que eles são fruto de inúmeros acontecimentos e de discussões e evoluções históricas extremamente importantes para a humanidade. Por conta disso, inspiraram inúmeras constituições federais, inclusive as brasileiras, como será exposto mais à frente.

\section{NECESSIDADE DE EVOLUÇÃO E EFETIVI- DADE DOS DIREITOS HUMANOS}

Ainda com relação à natureza dos Direitos Humanos, além de apresentar a convicção de que esses são construções históricas, Bobbio também demonstra que são mutáveis, dinâmicos e aptos a serem aprimorados e expandidos. Essa historicidade reflete que os direitos humanos não nasceram de uma única só vez, mas foram forjados por circunstâncias e estão sujeitos a serem ampliados por outros elementos ao longo dos anos, conforme a necessidade dos povos, conforme já explanado.

Assim, para Bobbio, o que tem aspecto de fundamentalidade numa determinada época histórica e civilização, pode não ter o mesmo aspecto em outras épocas ou em outras nações (2004). Porém, o que não se pode admitir é o retrocesso, a retração e a diminuição daquilo que já foi conquistado.

Dessa forma, ainda que o pleno desenvolvimento do homem seja prioridade, é importante ressaltar que até mesmo os direitos fundamentais à promoção da dignidade humana, não são ilimitados, uma vez que a Declaração dos Direitos Humanos das Nações Unidas, prevê expressamente, em seu artigo 29 a relatividade destes direitos:

Todo o homem tem deveres para com a comunidade, na qual o livre e pleno desenvolvimento de sua personalidade é possível.

No exercício de seus direitos e liberdades, todo o homem estará sujeito apenas às limitações determinadas pela lei, exclusivamente com o fim de assegurar o devido reconhecimento e respeito dos direitos e liberdades de outrem e de satisfazer as justas exigências da moral, da ordem pública e do bem-estar de uma sociedade democrática.

Esses direitos e liberdades não podem, em hipótese alguma, ser exercidos contrariamente aos objetivos e princípios das Nações Unidas. Nenhuma disposição da presente Declaração pode ser interpretada como o reconhecimento a qualquer Estado, grupo ou pessoa, do direito de exercer qualquer atividade ou praticar qualquer ato destinado à destruição de quaisquer direitos e liberdades aqui estabelecidos. (2004,p.13)

Mas Norberto Bobbio também traz à discussão, que tão importante quanto a positivação dos direitos humanos, é a efetividade e a evolução dos mesmos. Assim, o autor explana que muitos direitos foram proclamados nas Declarações, garantidos pelo constitucionalismo e, assim, estão revestidos de solenidade, mas despidos da necessária efetividade para o indivíduo possa usufruí-los em sua essência.

Nada impede que se use o mesmo termo para indicar direitos apenas proclamados numa declaração, ate mesmo solene, e direitos efetivamente protegidos num ordenamento jurídico inspirado nos princípios do constitucionalismo, onde haja juizes imparciais e várias formas de poder executivo das decisões dos juizes num ordenamento jurídico inspirado nos princípios do constitucionalismo, onde haja juízes imparciais e várias formas de poder executivo das decisões dos juízes. Mas entre uns e outros há uma bela diferença! já a maior parte dos direitos sociais, os chamados direitos de segunda geração, que são exibidos brilhantemente em todas as declarações nacionais e internacionais, permaneceu no papel. $\mathrm{O}$ que dizer dos direitos de terceira e de quarta geração? A única coisa que até agora se pode dizer é que são expressão de aspirações ideais, às quais o nome de "direitos" serve unicamente para atribuir um título de nobreza. Proclamar o direito dos indivíduos, não importa em que parte do mundo se encontrem (os di- 
reitos do homem são por si mesmos universais), de viver num mundo não poluído não significa mais do que expressar a aspiração a obter uma futura legislação que imponha limites ao uso de substâncias poluentes. Mas uma coisa é proclamar esse direito, outra é desfrutá- lo efetivamente. A linguagem dos direitos tem indubitavelmente uma grande função prática, que é emprestar uma força particular às reivindicações dos movimentos que demandam para si e para os outros a satisfação de novos carecimentos materiais e morais; mas ela se torna enganadora se obscurecer ou ocultar a diferença entre o direito reivindicado e o direito reconhecido e protegido (BOBBIO, 2004, p. 29).

Para Bobbio, não basta a mera proclamação dos Diretos dos Homens, é preciso a promoção dos mecanismos para que não se limitem ao campo das ideias e tomem força de prática e ação.

A respeito dos direitos sociais, Bobbio (2004) alerta para a realidade de países em desenvolvimento não conseguirem desenvolvê-los de modo satisfatório. Mais precisamente a respeito do direitos do trabalho, o autor destacou que não basta a proclamação, fundamentação ou proteção. Este somente poderia encontrar a sua eficácia máxima a partir da evolução da sociedade.

Aliás, a tendência de flexibilizar e até mesmo de extirpar os direitos fundamentais, inclusive os sociais, parece ser uma tendência acentuada dos dias atuais, prestes a corromper de forma incisiva tanto a democracia quanto a paz, elementos definidos por Bobbio como problemas fundamentais, que, quando violados, comprometem a estabilidade social.

A princípio, a enorme importância do tema dos direitos do homem depende do fato de ele estar extremamente ligado aos dois problemas fundamentais do nosso tempo, a democracia e a paz. O reconhecimento e a proteção dos direitos do homem são a base das constituições democráticas, e, ao mesmo tempo, a paz é o pressuposto necessário para a proteção efetiva dos direitos do homem em cada Estado e no sistema internacional. Vale sempre o velho ditado
- e recentemente tivemos uma nova experiência - que diz inter arma silente leges. Hoje, estamos cada vez mais convencidos de que o ideal da paz perpétua só pode ser perseguido através de uma democratização progressiva do sistema internacional e que essa democratização não pode estar separada da gradual e cada vez mais efetiva proteção dos direitos do homem, democracia e paz são três momentos necessários do mesmo movimento histórico: sem direitos do homem reconhecidos e efetivamente protegidos não existe democracia, sem democracia não existem as condições mínimas para a solução pacífica dos conflitos que surgem entre os indivíduos, entre grupos e entre as grandes coletividades tradicionalmente indóceis e tendencialmente autocráticas que são os Estados, apesar de serem democráticas com os próprios cidadãos (BOBBIO, 2004).

Se os Direitos Humanos se prestam a promover a paz e o desenvolvimento dos indivíduos, como de fato se prestam, encontram barreira para seu pleno potencial assecuratório da dignidade humana não somente na falta de efetivação de muitos deles, mas também no processo contrário, ou seja, na tendência bastante acentuada que há em desconsiderar o caráter de fundamentabilidade e assim, promover a flexibilização daquilo que, ao menos em tese, não deveria ser nem ao menos mitigado.

\section{INFLUÊNCIAS DA DECLARAÇÃO UNIVER- SAL DOS DIREITOS HUMANOS DE 1948 NA CONSTITUIÇÃO FEDERAL DE 1988.}

A Carta de 1988 é considerada como um marco jurídico de transição democrática e da institucionalização dos direitos humanos no país (PIOVESAN, 2015), fruto de um extenso processo de democratização, iniciado após vinte e um anos de ditadura militar que perdurou de 1964 a 1985.

Assim, a Constituição Federal de 1988 institucionalizou um regime politico democrático, e inegavelmente, foi responsável por colocar novamente o Brasil no cenário internacional, ao lado de nações que também resguardam e promovem a defesa e garantias fundamentais 
ao ser humano. Portanto, a Carta de 1988 se relaciona com todo o arcabouço internacional de proteção aos direitos humanos, considerando cada um deles como uma unidade indivisível, interdependentes e inter-relacionados.

Nesta sistemática, observa-se que a Constituição Federal adotou uma divisão a partir da qual o termo "direitos fundamentais" é gênero dividido em espécies, quais seja, direitos individuais, coletivos, sociais, nacionais e políticos. Assim, observa-se que as Constituições escritas estão vinculadas às declarações de diretos fundamentais. Aliás, a própria Declaração dos Direitos Humanos de 1948 cita como um dos motivos determinantes da Carta, o comprometimento dos povos em zelar pelos direitos, garantias e liberdades fundamentais.

Ao analisar a Constituição Federal Brasileira de 1988 é possível observar que todas essas dimensões, gerações ou fases dos direitos descritos por Bobbio, delinearam os direitos fundamentais dos cidadãos, estando dispostos como direitos sociais e individuais, no preâmbulo. Já os direitos e deveres individuais e coletivos, constam do Capítulo I do Título II, direitos humanos, dispostos no art. $4^{\circ}$, II, direitos e liberdades fundamentais, art. $5^{\circ}, \mathrm{XLI}$, direitos e liberdades constitucionais, no art. $5^{\circ}$, LXXI, direitos civis, art. $12, \S 4^{\circ}$, direitos fundamentais da pessoa humana, art.17, caput, direitos da pessoa humana, art. 34 , VII, b, direitos e garantias individuais, art. $60, \S 4^{\circ}$, IV e direito público subjetivo, no art. $208, \S 1^{\circ}$.

Há de se considerar que os direitos sociais são os mais relevantes para o presente estudo, mais especificamente os direitos ao trabalho e ao lazer. Neste sentido, é salutar observar que a Constituição Federal de 1988 enquadra o trabalho como um dos princípios gerais da atividade econômica, declarando como tais a valorização do trabalho humano e da livre iniciativa (art.170) e busca do pleno emprego (artigo 170,VIII). Entre os direitos e garantias fundamentais inclui o direito ao livre exercício do trabalho, oficio e profissão, atendidas as qualificações profissionais que a lei estabelecer.

Portanto, ainda que carente de efetivação, os direitos fundamentais do indivíduo encontram na atual Constituição Federal, aquilo que se apresenta como o padrão mínimo existencial para uma existência digna (BARUFFI,2010). Assim, nota-se que há no art. $60, \S 4^{\circ}$. Inc. IV, CF, elementos que não podem ser objeto de delibe- ração. Ou seja, não será jamais permitido que as propostas de emenda constitucional, causem a abolição das garantias individuais de uma forma geral, não somente dos direitos sociais, mas de todos aqueles considerados fundamentais. Existe, portanto, uma barreira, um escudo que se constitui uma medida de proteção em torno dos direitos fundamentais, já que são elementos que vão garantir a continuidade da Constituição.

\section{AS CONTRIBUIÇÕES DAS ENCÍCLICAS "PACEM IN TERRIS" E "RERUM NOVARUM" PARA OS DIREITOS AO TRABALHO E AO LA- ZER}

Após as duas grandes guerras, o mundo passou a voltar a atenção para a construção de ordenamentos que pudessem promover a paz e a dignidade da pessoas humana. Dessa forma, a Declaração Universal dos Direitos Humanos de 1948 inspirou a escrita dos mais diversos tipos de documentos que visavam à sua ampliação e a positivação.

Mas é de se observar que inclusive instituições religiosas, como a Igreja Católica Apostólica Romana, engajaram-se na luta e manifestaram-se a respeito dos direitos humanos, através de alguns documentos escritos pelos papas. Um deles, ainda que escrito anteriormente à Declaração de 1948, é apto a atestar a historicidade dos direitos humanos, uma vez que revela a preocupação da Igreja Católica com o tratamento que estava sendo dispensado aos trabalhadores da época. Datada de 1891 e escrita por pelo Papa Leão XIII, o documento abordou a "questão social", delineando inclusive quais eram as obrigações tanto de patrões quanto de empregados.

Nota-se a ênfase na necessidade e no respeito no trato com a classe trabalhadora, com a severa condenação à opressão, enfatizando o respeito e a dignidade dos trabalhadores. Dessa forma, a Encíclica "pontifica uma fase de transição para a justiça social, traçando regras para a intervenção estatal na relação entre trabalhador e patrão."(MARTINS, 2011). Assim, quando fala da obrigação dos operários e dos patrões, o documento reforça que todo trabalho deve ser digno, isento de humilhações e discriminações.

Quanto aos ricos e aos patrões, não devem tratar o operário como escravo, mas respeitar nele a dignidade 
do homem, realçada ainda pela do Cristão. O trabalho do corpo, pelo testemunho comum da razão e da filosofia cristã, longe de ser um objecto de vergonha, honra o homem, porque the fornece um nobre meio de sustentar a sua vida. O que é vergonhoso e desumano é usar dos homens como de vis instrumentos de lucro, e não os estimar senão na proporção do vigor dos seus braços. $\mathrm{O}$ cristianismo, além disso, prescreve que se tenham em consideração os interesses espirituais do operário e o bem da sua alma. Aos patrões compete velar para que a isto seja dada plena satisfação, para que o operário não seja entregue à sedução e às solicitações corruptoras, que nada venha enfraquecer o espírito de família nem os hábitos de economia. Proíbe também aos patrões que imponham aos seus subordinados um trabalho superior às suas forças ou em desarmonia com a sua idade ou o seu sexo (LEÃO XIII, 1891).

Portanto, é possível observar a preocupação com a dignidade humana do trabalhador estampada nas linhas da Rerum Novarum, inclusive com ênfase no cuidado com o trata espiritual e físico.

Já a Carta Encíclica Pacem in Terris, do Papa João XXIII, de abril de 1963, fala a respeito de várias diretrizes e preceitos dirigidos não somente aos padres, bispos, arcebispos, ao membros do clérigo de uma forma em geral, aos católicos, e também a todos "homens de boa vontade", revelando seu caráter ecumênico e abrangente. Suas recomendações eram no sentido de promover uma sociedade mais justa, com valores sólidos que promovessem e conservassem a dignidade da pessoas humana. Assim, a oitava e última Encíclica do Papa João XXIII, é considerada a Encíclica da Paz e da dignidade humana e ressalta a importância da colaboração mundial para promoção da paz e de uma sociedade equilibrada e justa.

O documento, obviamente tem a menção de conceitos religiosos, mas traz em seu corpo também, a demonstração de que a Igreja Católica estava com sua atenção voltada para os valores sociais que deveriam ser exercidos num mundo que ainda buscava se recuperar das barbáries, depois das duas grandes guerras. $\mathrm{O}$ texto demonstra que João XXIII recomendava o reconhecimento da dignidade de todos os seres humanos. Assim, referiu-se à Declaração Universal dos Direitos Humanos de 1948, e que se tornou uma referência e uma inspiração para os povos empenhados na afirmação dos princípios e valores democráticos, buscando uma integração dinâmica entre os direitos e deveres individuais, os direitos e deveres políticos e os direitos e deveres sociais. Mais um elemento que corrobora para o conceito de universalidade tanto da Declaração, quanto dos próprios Direitos Humanos.

Segmentos da sociedade da época abrem o seu olhar e voltam a sua atenção para a ascensão econômico-social das classes trabaIhadoras, o ingresso da mulher na vida pública, o fim do colonialismo e das discriminações sociais, a participação das pessoas na vida política e social do país, apontando, ainda que não explicitamente, para o modelo da democracia participativa e a necessidade e a urgência da paz no interior das comunidades nacionais e da comunidade internacional. É o que se observa na Encíclica Pacem in Terris, especificamente no que diz respeito ao trabalho e a importância do mesmo para a formação do indivíduo:

\section{[...] \\ 18. No que diz respeito às atividades econômicas, é claro que, por exigên- cia natural, cabe à pessoa não só a liberdade de iniciativa, senão tam- bém o direito ao trabalho. \\ 19. Semelhantes direitos comportam certamente a exigência de poder a pessoa trabalhar em condições tais que não se the minem as forças fí- sicas nem se lese a sua integridade moral, como tampouco se compro- meta o são desenvolvimento do ser humano ainda em formação.}

É importante observar que há uma ênfase de que, para que haja a garantia de dignidade ao indivíduo, esse deve ter acesso ao trabalho, de forma que garanta seu sustento, mas também desenvolva seus valores como ser humano. Há também a menção de que tal trabalho não pode ser penoso, nem esgotar as forças físicas, de forma que ofenda a sua honra.

Ou seja, aquilo que nasceu para ser um direito, para garantir qualidade de vida, uma existência digna, deve, necessariamente cumprir a 
sua função. Neste sentido, Hannah Arendt, ${ }^{3}$ em seu livro "A condição Humana", traça reflexões a respeito do trabalho, uma das atividades mais essenciais para o ser humano, que se presta não somente a promover o próprio sustento, mas também a definir a identidade do indivíduo, uma vez que reflete a sua própria condição de humanidade.

Dessa forma, estabelece um paralelo entre o que é o trabalho, labor e obra, elementos que ela caracteriza como vita activa, Diante do cenário de desenvolvimento industrial da Europa e a consequente expansão da classe operária, a autora questiona "o que estamos fazendo?", numa referência à análise necessária ao exercício dos direitos conquistados e da inserção do indivíduo na vida política, através da formação da sua identidade social e formação da sua singularidade. Através disso, o homem poderia se revelar ao mundo como homem, mas, do contrário, promovido o isolamento, instaura-se o regime totalitário.

Aliás, os regimes totalitários inspiraram Arendt a questionar a organização política adotada pela sociedade moderna e sobre quais motivos e elementos são produzidos pelo próprio homem, a ponto de submeter toda uma sociedade a tais regimes opressores, e assim, mitigando ou até mesmo eliminando os direitos humanos. Em sua obra, "As origens do totalitarismo", a autora expõe que a solidão e o desamparo são as bases para a implantação de tal regime. Assim, tais elementos fazem com que o homem não se sinta pertencente ao mundo, ainda que seja um homo faber, ou seja, alguém produtivo, mas supérfluo, sem uma vida privada. (ARENDT, 2000)

Tal introdução do pensamento de Hannah Arendt é necessária, pois assim será possível compreender os questionamentos feitos em "A condição humana", a respeito daquilo que é produzido/desenvolvido pelo homem através do labor, trabalho e ação, explicando o que real-

\footnotetext{
${ }^{3}$ Hannah Arendt contribuiu de forma exponencial ao pensamento contemporâneo, não somente pelo profundo conhecimento da Filosofia Clássica, mas também pela forma original e única de interpretar a Filosofia Moderna, além de seu sensível e preciso olhar humanista do indivíduo. Seu pensamento traz luz ao estudo dos Direitos Humanos, definindo o ser humano não somente como detentor de direitos, mas sim como alguém que, aos exercê-los, pode sempre se aprimorar como indivíduo em todas as esferas da sua identidade. O pensamento de Arendt traduz que, para que haja o bem comum, é preciso não somente respeitar mas desenvolver os direitos fundamentais dos indivíduos, de que forma que os mesmos possam se expandir em todas as suas potencialidades, e, consequentemente, formar uma sociedade mais equilibrada e justa.
}

mente pode e deve ser produtivo e o que nada acrescenta ao homem.

Os dois conceitos mais importantes para este estudo são os apresentados por Arendt: "labor" e "trabalho". Ao definir labor, Hannah Aren$\mathrm{dt}$ esclarece que sempre está ligado a fadigas, ao esforço e à dor, que geram a deformação do ser humano. O labor está intimamente ligado ao processo biológico do ser humano e assegura a sobrevivência do indivíduo e também de toda espécie. Assim, "a condição humana do labor é a própria vida", segundo Arendt. Cumpre ressaltar que para a filósofa, o labor também está diretamente associado ao consumo, elementos de um só processo.

Por outro lado, o trabalho é tudo aquilo produzido pelo homem; "a condição humana do trabalho é a mundanidade". Produz um pouco mais de significado à vida, em que pese o seu caráter fútil, por meio da permanência e durabilidade. Mas, tanto o labor quanto o trabalho estão associados ao fluxo da vida, à "Vida Activa", à existência e perpetuação da espécie, uma vez que preparam o mundo para o recebimento das novas gerações.

A partir das reflexões de Hannah Arendt, é possível compreender que muitos indivíduos estão de fato laborando, inseridos na sociedade de consumo, mas nem todos alcançaram o patamar de usufruir o prazer e a alegria de trabalhar, já que, segundo a autora, o trabalho está erroneamente associado à falta de lazer, sendo que o primeiro excluiria o segundo.

Diz-se frequentemente que vivemos numa sociedade de consumidores; e uma vez que, como vimos, o labor e o consumo são apenas dois estágios de um só processo, importo ao homem pelas necessidades da vida, isto é o mesmo que dizer que vivemos numa sociedade de operários ("labores"), ou seja, de homem que "laboram".

(...) Essa sociedade não surgiu em decorrência da emancipação das classes trabalhadoras, mas resultou da emancipação da própria atividade do labor, séculos antes da emancipação politica dos trabalhadores. $O$ importante não é que, pela primeira vez na história, os operários tenham sido admitidos com iguais direitos na 
esfera pública, e sim que quase conseguimos nivelar todas as atividades humanas, reduzindo-as ao denominado comum de assegurar as coisas necessárias à vida e de produzi-las em abundância. $O$ que quer que façamos, devemos fazê-lo a fim de "ganhar o próprio sustento".

(...)A mesma tendência de reduzir todas as atividades sérias à condição de prover o próprio sustento é evidente em todas as atuais teorias de trabalho, que quase unanimemente definem o trabalho como o oposto ao lazer. Em consequência, todas as atividades sérias, independentemente dos frutos que produzam, são chamadas de "trabalho", enquanto toda atividade que não seja necessária, nem para a vida do indivíduo nem para o processo vital da sociedade, é classificada como lazer (ARENDT, 1993, p.138 e 139).

Dessa forma, percebe-se que desde o início, o conceito de que quem trabalha não tem lazer, é bastante inerente à definição do trabalho e do labor. A inserção do indivíduo na sociedade de consumo (ou também denominada "promoção do sustento") era, e ainda é, a prioridade daquele que labora. O resto é supérfluo, é luxo. Aliás, Arendt também acrescenta que o labor não evoluiu a ponto de extirpar a ideia de que "toda atividade não relacionada com o labor torna-se 'hobby'". Ou seja, o indivíduo deveria eleger entre aquilo que lhe seria aprazível e o próprio sustento. Até hoje esta necessidade de escolha se repete. Mas, inserido numa sociedade em que consumir é sobreviver e para sobreviver é preciso trabalhar, o indivíduo elege o trabalho e sacrifica o lazer.

É importante ressaltar que Hannah Arendt fala a respeito de Direitos Humanos com a propriedade de quem não somente assistiu a violação cruel dos direitos de toda uma nação, mas de quem sofreu as dores de um dos períodos mais reprováveis da raça humana, no que diz respeito a violação de tais direitos. Talvez daí justifique sua identidade com o humanismo e com a capacidade de olhar o indivíduo com uma visão tão profunda a ponto de questionar se os direitos aos quais ele está recebendo acesso, de fato estão promovendo transformação positiva e aprimoramento da sua essência. E assim ela expõe que o lazer não exclui o trabalho, uma vez que se complementam e ambos são inerentes à condição humana.

Ou seja, ainda que não trate abertamente a respeito dos Direitos Humanos, nem mesmo use tal terminologia, o pensamento de Arendt a respeito da condição humana muito contribui para a análise sua da importância prática, uma vez que traz reflexões sobre de que forma os direitos já conquistados podem ou não promover ou preservar a dignidade humana do indivíduo. Cabe, neste contexto, pensar a respeito da forma como são exercidos.

Assim, através deste conceito sobre trabalho e lazer, é possível adentrar nas definições de importância para o indivíduo, tanto do direito do trabalho, quanto do direito ao lazer, ainda sob a égide de que ambos são definidos como direitos fundamentais, ainda que o segundo padeça de efetivação.

\section{O DIREITO SOCIAL AO TRABALHO}

Tão difícil quanto proteger, preservar e fomentar mecanismos para a sua evolução, é dar visibilidade aos Direitos Humanos. No que diz respeito aos grupos de direitos sociais, o direito do trabalho nem sempre é considerado como um direito humano.

Acompanhando os ventos do constitucionalismo social do início do século $X X$, o direito do trabalho, como princípio fundamental, é inserido na Constituição Federal de 1937. A partir deste importante marco, várias leis foram promulgadas a fim de assegurar direitos aos trabalhadores. Assim, em 1943, houve a Consolidação das Leis do Trabalho, pelo Decreto-Lei 5.452 de $1^{\circ}$ de maio de 1943, a CLT. Em seguida, várias inovações ocorreram no sentido de fortalecer ainda mais as relações trabalhistas, inclusive com alguns constando na Constituição Federal de 1946, mas foi com a promulgação da Carta Magna em 1988, com o apogeu do processo de democratização do país, que houve a ampliação considerável dos direitos sociais, particularmente, dos direitos trabalhistas.

Nota-se, portanto, que o direito ao trabalho e seus desdobramentos são assegurados na Declaração dos Direitos Humanos de 1948 e, mais tarde, vieram a refletir diretamente na estruturação da Consolidação das Leis do TrabaIho brasileira (BARROS,2008). 
No âmbito trabalhista brasileiro, a previsão constitucional é o sinal da evolução dos direitos humanos de um modo geral e do reconhecimento da importância deste direito para a vida do ser humano e para o próprio trabalhador. Assim, há no art. $60, \S 4^{\circ}$. Inc. IV, CF, elementos que não podem ser objeto de deliberação. Ou seja, não deveria ser jamais permitido que as propostas de emenda constitucional, causassem a abolição das garantias individuais.

Nota-se, portanto, que o direito ao trabaIho e seus desdobramentos e também o direito ao lazer, são assegurados na Declaração dos Direitos Humanos e, mais, vieram a refletir diretamente na estruturação da Consolidação das Leis do Trabalho brasileira (BARROS, 2008).

Assim, a Declaração dos Direitos Humanos em seus artigos 23 e 24, faz a previsão expressa de que o trabalho e aspectos inerentes, devem ser objeto de atenção e proteção, bem como o direito ao lazer, uma vez que preconiza que é direito de toda pessoa o repouso, o lazer, a limitação razoável da jornada de trabalho e inclusive de férias periódicas remuneradas. Tais preceitos estão dispostos não somente nos artigos da CLT, mas em leis complementares, no intuito de assegurar a dignidade humana do trabalhador.

\section{O DIREITO SOCIAL AO LAZER DO TRABA- LHADOR}

Como dito, tão essencial à promoção da dignidade do ser humano quanto qualquer outro direito fundamental, é o direito do trabalho. E para o trabalhador, é indispensável o lazer. Porém, tal direito, ainda que seja essencial, não é efetivado no ordenamento jurídico brasileiro, ainda que esteja expressamente declarado na Constituição Federal.

Aliás, nem mesmo há um consenso na definição do que seria o direito ao lazer do trabalhador. Ao tentar definir o tema, Bolzan de Morais(1995) estabelece que está intimamente ligado à qualidade de vida do individuo e embora não defina quais são os parâmetros adotados para tal conceito. Assegura que vão muito além das pretensões de consumo, daquilo que o homem pode adquirir com o seu trabalho e do estilo de vida que passa a ter como fruto do seu labor. Assim, o arcabouço teórico que define "qualidade de vida e lazer", carrega em seu bojo também as opções que o indivíduo tem no momento em que não estiver trabalhando (CALVET,2006; LEITE, 1995).

Mas o lazer pode ser um conjunto de ocupações as quais o indivíduo consegue entregar-se de livre vontade, seja para repousar, seja para divertir-se, recrear-se e entreter-se ou, ainda, para desenvolver sua informação ou formação desinteressada, sua participação social voluntária ou sua livre capacidade criadora após livrar-se ou desembaraçar-se das obrigações profissionais, familiares e sociais (DUMAZEDIER, 2004).

As discussões a respeito do caráter jurídico do direito ao lazer ainda são esparsas e precárias, se considerado que o direito ao lazer possui caráter de fundamentabilidade tal como os direitos à saúde, educação e moradia. Por isso, é preciso construir um entendimento a partir de conceituações que revelem a importância tanto do direito ao trabalho como dos direitos sociais fundamentais propriamente ditos.

Para construir esta conceituação jurídica, também são salutares as reflexões de Magnani (1994), a respeito da origem do lazer na história. O sociólogo apresenta a Revolução Industrial como o que parece ser o embrião tanto do direito do trabalho quanto do direito ao lazer. Era a passagem do seu modo de vida tradicional, rural e de autossubsistência para a relação de emprego que se formava aos poucos. Inserido neste contexto, o limite da exaustão física era o único limite conhecido pelo homem trabalhador.

O nascente capitalismo, porém,
inaugura uma nova ordem socio-
-econômica onde a produção já não
era determinada pelas necessidades
de consumo do grupo doméstico,
mas tinha como eixo o mercado, que
aliás fornecia um dos fatores envol-
vidos no processo produtivo: a força
de trabalho. O problema da conser-
vação desta última dizia respeito
unicamente a seu vendedor que, de
posse da remuneração, devia arcar
com os custos - alimentação, aloja-
mento, saúde, descanso (MAGNANI,
1994).

Neste mesmo sentido, Lafargue (2000) alerta que o lazer do trabalhador, somente é possível a partir da limitação labor. E para que isso aconteça, cabe primeiramente ao próprio trabalhador ter e exercer a consciência de que 
deve lutar para buscar assegurar tempo para si mesmo e para o desenvolvimento de sua individualidade, afinal, tantos outros aspectos de sua vida necessitam de atenção, não somente o trabalho. Caso não seja possível, então haverá a eterna servidão ao trabalho, que não mais se apresentará como forma de promoção da sobrevivência, mas sim como um instrumento de tortura do terrível algoz, o capitalismo.

Se, extirpando do peito o vício que a domina e que avilta sua natureza, a classe operária se levantasse em sua força terrível, não para exigir os Direitos do Homem, que não passam dos direitos da exploração capitalista; não para reivindicar o Direito ao Trabalho, que não passa do direito à miséria, mas para forjar uma lei de bronze que proíba o trabalho além de três horas diárias, a terra, a velha Terra, tremendo de alegria, sentiria brotar dentro de si um novo universo... Mas como exigir de um proletário corrompido pela moral capitalista uma decisão tão viril? Como Cristo, dolente personificação da escravidão antiga, os homens, mulheres e crianças do proletariado sobem penosamente, há um século, o duro calvário da dor; há um século, o trabalho forçado quebra seus ossos, mata suas carnes, esmaga seus nervos; há um século, a fome retorce suas entranhas e alucina suas mentes!... Preguiça, tenha piedade de nossa longa miséria! Preguiça, mãe das artes e das virtudes nobres, seja o bálsamo das angústias humanas! (LAFARGUE, 2000).

Assim, o capitalismo, a necessidade de estar inserido no mundo globalizado que produz e consome desenfreadamente, não raramente condiciona o homem a priorizar tão somente o seu meio de sobrevivência, o trabalho

Portanto, o trabalho, o exercício de uma função, profissão e/ou ofício era (e ainda é) algo indispensável não somente para mover uma sociedade com suas necessidades e ofertas e assim fazer girar a grande roda de uma estrutura econômica-social, mas também, sob a ótica do indivíduo em si, trazer dignidade ao ser humano, uma vez que torna possível alcançar a paz de espírito, através da promoção do seu próprio sustento e o sustento da sua família e depen- dentes (OLIVEIRA,2010). Por isso, está enquadrado no grupo dos direitos fundamentais, grupo este, fruto da evolução social ao longo dos anos em todo o mundo.

Portanto, é preciso ressaltar a sua fundamentabilidade, destacando sempre o desenvolvimento existencial do ser humano, em tudo aquilo que ele é capaz de ser e fazer. E como resume Calvet (2006) quando define juridicamente o direito ao lazer "como o direito fundamental do homem de se desenvolver como ser humano dotado de razão e desejo, na busca de sua elevação física, psíquica, social e espiritual, estimulando e aprimorando seus talentos e capacidades no interesse que bem lhe aprouver".

Ademais, se o direito ao lazer está incluído no rol dos direitos fundamentais, é pelo fato de ter sido autenticado pelo Estado para propiciar uma vida mais digna ao indivíduo. Porém, não requer apenas a intervenção do Poder Público para que possa ir ao seu máximo efeito, mas também exige o respeito nas relações particulares, especificamente, entre patrões e empregados, ainda que seja uma norma de aplicação imediata.

Porém, apesar de estar previsto na Constituição Federal de 1988 e de ser uma norma de aplicação imediata, o direito ao lazer não foi sistematizado no ordenamento jurídico brasileiro. Além disso, não existe na Constituição Federal e nem na lei infraconstitucional, dispositivo que defina o que é o lazer do trabalhador, nem mesmo na Consolidação das Leis Trabalhistas ou até mesmo na "Reforma Trabalhista" que entre em vigor em novembro de 2017, possui em seu bojo qualquer artigo que traga a definição jurídica do que é o que é lazer e como pode (e se pode) o trabalhador ter acesso a ele.

O que se percebe é que, com o excesso de labor, o indivíduo passa a ter cada vez menos tempo e vontade de pensar em si mesmo e desenvolver outros aspectos inerente a sua personalidade e identidade. Muitas vezes o obreiro se dá conta de que teve sua saúde e vida social atingidos e prejudicados com o excesso de labor e que não possui nem tempo livre nem mesmo acesso a nenhum tipo de lazer.

Muitos trabalhadores em todo o país têm ingressado com reclamatórias trabalhistas, pleiteando dano moral pela supressão ao lazer, geralmente acompanhado por pedidos de pagamento de horas-extras. Assim, tem cabido aos tribunais trabalhistas verificar a violação desse 
direito, e ponderar se a compensação financeira é eficaz para mitigar os efeitos da mesma.

\section{CONSIDERAÇÕES FINAIS}

Quase setenta anos depois da sua proclamação, a Declaração Universal dos Direitos Humanos de 1948 continua sendo um dos mais importantes documentos na positivação de tais direitos, responsável, inclusive, por significativas contribuições na construção de ordenamentos jurídicos e de elementos importantes da democracia em diversas nações. Acima de tudo, foi um importante marco na regulamentação de princípios amplos e universais nas relações sociais. Assim, foi a partir desse processo de positivação, que os direitos humanos passaram do status de orientações éticas ou programas de ação e alcançaram o patamar de obrigações jurídicas que vinculam as relações internas e externas dos Estados.

Este cenário demonstra que os direitos do homem são de fato construções histórias, mas são também produto da dialética entre a conceituação moral e ética e também do esforço jurídico-político, responsável por sua efetivação. Dessa forma, a Declaração dos Direitos Humanos de 1948 influenciou a elaboração das Constituições de muitos países, inclusive da brasileira, de 1988. No âmbito trabalhista brasileiro, a previsão constitucional é o sinal inequívoco da evolução dos direitos humanos de um modo geral e do reconhecimento da importância deste direito para a vida do ser humano e para o próprio trabalhador. Na Carta Magna, os direitos humanos foram consagrados, recebendo a denominação de direitos fundamentais, revestidos da blindagem da inalterabilidade. Ou seja, não poderia, jamais serem eliminados nem ao menos diminuídos.

Assim, é possível concluir que a historicidade dos Direitos Humanos apontada por Bobbio explica a evolução de muitos direitos fundamentais ao longo dos anos. Este aspecto do direitos humanos traduz a própria jornada dos direitos trabalhistas, que surgiram, primeiramente na Constituição de 1937, para somente serem consolidados em 1943, que apesar de não ser um código propriamente dito, reuniu as principais leis trabalhistas. Aliás, tais leis foram recepcionadas pela Constituição de 1988 , sendo que muitos direitos trabalhistas foram reconhecidos como direitos fundamentais.
Porém, trajetória ainda singela é a do direito ao lazer, pois, ainda que positivado na Constituição Federal, não encontra respaldo no ordenamento jurídico brasileiro, de modo que seja plenamente efetivado. $E$ por não possuir a garantia da efetividade, é passível de violação. Aliás, nem mesmo existe uma definição do que é o lazer ou de que forma o trabalhador poderia ter acesso a ele.

Mas, na contra mão dessa recomendação de limitação razoável de jornada, o que comumente ocorre na prática, é a sua supressão através de jornadas elastecidas e sistemáticas empresariais que sacrificam não somente o tempo vago do trabalhador, mas também as suas forças físicas e a sua vitalidade. Assim, apesar de ser um direito social, sua visibilidade é tão precária quanto sua efetividade e certamente sua supressão é uma violação aos direitos humanos uma vez que promove a coisificação do ser humano, condicionado a apenas trabalhar para ter, sem se preocupar com outro elementos importantes do seu ser, como ter tempo para si mesmo.

Neste estudo, foi possível observar que o pensamento de Hannah Arendt revela a importância para o desenvolvimento do ser humano, tanto do trabalho quanto do lazer. A filósofa aponta que não há necessidade de um direito excluir o outro, sendo que ambos são inerentes à condição humana e se prestam a evitar que o ser humano seja coisificado. Ou seja, o indivíduo pode perfeitamente ser um trabalhador que desfruta de uma atividade que promove seu sustento, mas que também tem acesso a momentos de lazer. Esse aspecto também reforça o ensinamento de Bobbio de que os direitos são indivisíveis e cumulativos. Aliás, compete à dignidade humana de todo indivíduo, jamais ter de abrir mão de algum direito para poder gozar de outro.

Dessa forma, tanto o direito ao trabalho quando o direito ao lazer, assim como os outros direitos relacionados na Declaração Universal dos Direitos Humanos, são indispensáveis para atender às várias necessidades básicas do indivíduo. Com o lazer, são sanadas necessidades como de libertação, contrapondo-se à angustia e ao peso que são experimentados na angústia que acompanham a vida do trabalhador, principalmente em atividades não escolhidas livremente.

Porém, é necessário destacar que, ape- 
sar dos Direitos Humanos serem históricos, não pressupõem uma evolução ao longo do tempo, em algumas de suas vertentes. Ou seja, nem sempre o passar dos anos e a sua positivação significa que o indivíduo está efetivamente usufruindo das conquistas. Um exemplo é o direito do trabalho. Nesta seara, várias conquistas estão sendo relativizadas e beirando a flexibilização, estejam revestido de fundamentalidade.

Da mesma forma, é possível observar que o direito ao lazer, apesar de ser previsto, não foi efetivado, ou seja, não evoluiu a tal ponto de ser regulamentado. Aliás, no que concerne ao direito ao lazer, é importante compreendê-lo no contexto dos direitos fundamentais, e neste caso, a origem desses a partir do desenvolvimento histórico das discussões sobre direitos naturais dos indivíduos, que culminou em 1948 com Declaração dos Direitos Humanos pela Organização das Nações Unidas, como já exposto.

Assim, o que se observa, é que por padecer da tão necessária efetividade, resta aos tribunais brasileiros analisar fatos concretos de violação ao referido dispositivo em demandas trabalhistas, para garantir a satisfação e/ou reparação deste importante direito do indivíduo, particularmente, do trabalhador.

Promover e proteger a dignidade humana é um dos principais objetivos das Declaração Universal dos Direitos Humanos de 1948 e de vários tratados internacionais, inclusive aqueles construídos para promover e conservar o trabaIho em condições dignas, além de promover o direito ao lazer do trabalhador. Neste ponto, há concordância com um dos princípios basilares do direito do trabalho. O indivíduo, por ser um ser holístico, precisa encontrar e desenvolver a vocação dos seus potenciais e o trabalho oferece possibilidades neste sentido. Assim, além de promover o próprio sustento e também de sua família, o trabalhador adquire identidade social, torna-se pertencente a um grupo, desenvolve suas habilidades, etc.

A história demonstra que os direitos humanos, de fato evoluíram. A declaração Universal de 1948 é o padrão mínimo que deve ser observado nas democracias em todo mundo, e foi capaz de inspirar governos e instituições na consolidação dos direitos dos homens. Porém, as lacunas nos ordenamentos jurídicos internos dos países, inclusive do Brasil, e os exemplos de violação, supressão e mitigação demonstram que a trajetória dos Direitos Humanos ainda é longa até a sua plena efetivação.

\section{REFERÊNCIAS}

ARENDT, H. A Condição humana. São Paulo: Editora Forense Universitária LTDA.1993.

Origens do totalitarismo. Trad. Roberto Raposo. SP: Cia das Letras, 2000.

BALDI, C. A. Direitos Humanos na Sociedade Cosmopolita. Rio de Janeiro: Renovar, 2004.

BARROS, A. M. de. Curso de Direito do Trabalho. 4. ed. São Paulo: LTr, 2008

BARUFFI, H. Os direitos sociais na Constituição de 1988 e algumas reflexões em torno de sua concretização. Anima: Revista Eletrônica do Curso de Direito da Opet, v. III, p. 80-97, 2010.

BOBBIO, N. A Era dos Direitos. 9. ed. Rio de Janeiro: Elsevier, 2004

BOLZAN DE MORAIS, J. L. Do direito social aos interesses transindividuais. Tese de Pós Graduação do Curso de Direito da UFSC. Florianópolis, 1995.

CALVET, O. A. Direito ao lazer nas relações de trabalho. São Paulo: LTr, 2006.

CASSAR, V. B. Direito do Trabalho. São Paulo: Editora Método, 2013.

CATECISMO DA IGREJA CATÓLICA. Edição típica vaticana. São Paulo: Loyola, 2000, §2246.

COMPARATO, F. K. A afirmação histórica dos direitos humanos. 4. ed. São Paulo: Saraiva, 2005.

DUMAZEDIER, J. Lazer e cultura popular. São Paulo: Perspectiva, 2004.

JOÃOXXIII, Papa. Encíclica do Papa João XXIII: "Pacem in Terris" - 1963. Disponível em: <http:// w2.vatican.va/content/john-xxiii/pt/encyclicals/ documents/hf_j-xxiii_enc_11041963_pacem. html>. Acesso em: 02 de dez. 2016

LAFARGUE, P. O direito à preguiça, claridade. 2000. São Paulo.

LAFER, C. A reconstrução dos Direitos 
Humanos - um diálogo com o pensamento de Hannah Arendt, São Paulo, Cia. das Letras, 1988.

LEÃO XIII, Papa, Carta Encíclica Rerum

Novarum. Disponível em: <http://w2.vatican. va/content/leo-xiii/pt/encyclicals/documents/ hf_I-xiii_enc_15051891_rerum-novarum.html.> Acesso em: $\overline{1} 3$ de dez. 2016.

MAGNANI, J. G. C. O lazer na cidade. Texto apresentado ao Condephaat. São Paulo, v. 4, 1994.

MARTINS, S. P. Direito do Trabalho. 27. ed. São Paulo: Atlas, 2011. p. 8.

OLIVEIRA, M. B. de. O direito ao lazer na formação do homem social. Âmbito Jurídico XIII, v. 76, 2010.

PIOVESAN, F. Diretos Humanos e o direito constitucional internacional. 15. ed. São Paulo: Saraiva, 2015.

\section{LA HISTORICIDAD DE LOS DERECHOS \\ HUMANOS Y LOS PENSAMIENTOS DE BOBBIO Y ARENDT EN LA CONSTRUCCIÓN DEL DERECHO AL TRABAJO Y AL OCIO}

Resumen: A partir de premisas apuntadas por Norberto Bobbio en su obra "La Era de los Derechos" y por Hannah Arendt, en su obra "La Condición Humana", se verifica la historicidad de los Derechos Humanos y su influencia en el ordenamiento jurídico brasileño, particularmente en la Constitución Federal de 1988 y en la construcción teórica, positividad y efectividad al derecho del trabajo y derecho al ocio del trabajador. Así, el enfoque principal está en la historicidad de los Derechos Humanos defendida por Bobbio y la importancia del derecho al trabajo y al ocio destacado por Hannah Arendt. Merece destaque también las Cartas Encíclicas Pacem in Terris y Rerum ovarum, que figuran como elemento importante en la historicidad de los Derechos Humanos, incluso en la construcción del Derecho del Trabajo.

Palabras clave: Derechos humanos; Derechos fundamentales; Derecho del trabajo; Derecho al ocio. 